\title{
Effects of Clostridium butyricum on antioxidant properties, meat quality and fatty acid composition of broiler birds
}

\author{
Xiudong Liao ${ }^{\dagger}$, Rujuan $\mathrm{Wu}^{\dagger}$, Guang Ma, Longmei Zhao, Zhaojun Zheng and Rijun Zhang*
}

\begin{abstract}
Background: Consumers are becoming increasingly interested in food containing high concentration of polyunsaturated fatty acids (PUFA). PUFA are considered as functional ingredients to prevent cardiovascular disease. The present study aimed to evaluate the effects of Clostridium butyricum on antioxidant properties, meat quality and fatty acid composition of broilers.
\end{abstract}

Methods: A total of 320 one-day-old Arbor Acres male chicks were randomly assigned to one of five treatments with eight replicates and fed a antibiotic-free basal corn-soybean meal diet (control) or the basal diet supplemented with either $2.5 \times 10^{8}(\mathrm{CB} 1), 5 \times 10^{8}$ (CB2) or $1 \times 10^{9}$ (CB3) cfu of C. butyricum $/ \mathrm{kg}$ or150 mg of aureomycin $/ \mathrm{kg}$ (antibiotic) for 42 days.

Results: The results showed that chicks fed diets supplemented with $C$. butyricum had higher $(P<0.05)$ superoxide dismutase activity and lower $(P<0.05)$ malondialdehyde concentration in liver compared with those in the control group. Broilers had lower $(P<0.05)$ cholesterol content of serum in either CB2 or CB3 treatment at day 21 and in the C. butyricum-supplemented groups at day 42 than those in the control group. Chicks fed CB3 diet had lower $(P<0.05)$ percentage of abdominal fat and higher $(P<0.05)$ breast muscle yield than those in the control and antibiotic groups. The supplementation of $C$. butyricum increased $(P<0.05)$ the concentrations of $C 20: 1 n-9, C 20: 2 n-6, C 20: 3 n-6, C 20: 3 n-3$, C20:4n-6, C20:5n-3, C22:6n-3 and total PUFA as well as ratio of PUFA to saturated fatty acids in breast muscle and the contents of C18:2 t-9, t-12, C20:3n-6, C20:3n-3 and C20:5n-3 in thigh muscle.

Conclusions: Supplementation of C. butyricum promotes hepatic antioxidant status, decreases cholesterol content of serum and percentage of abdominal fat, and improves meat quality and fatty acid composition of broiler birds. The results from the present study indicate that the increased PUFA concentrations in meat of broilers fed C. butyricum might be attributable to enhanced antioxidant activity.

Keywords: Clostridium butyricum, Antioxidant properties, Meat quality, Fatty acid

\section{Background}

The alteration of animal lipids has long been studied but still receives a lot of attention in research because of its implications for human health [1,2]. Furthermore, consumers are becoming increasingly interested in food containing high amount of polyunsaturated fatty acids (PUFA). PUFA are considered as functional ingredients to prevent cardiovascular disease and other chronic diseases

\footnotetext{
* Correspondence: feedbiotech@yahoo.com

${ }^{\dagger}$ Equal contributors

Laboratory of Feed Biotechnology, State Key Laboratory of Animal Nutrition, College of Animal Science and Technology, China Agricultural University, Beijing 100193, People's Republic of China
}

$[3,4]$. Chicken meat is considered one of the most desirable meats all over the world as a result of relatively low fat content and high concentration of PUFA [5]. Moreover, meat quality and fatty acid composition of poultry can be easily modified by dietary mean [6,7]. Some studies indicated that dietary supplementation of probiotics (Lactobacillus and Rhodobacter capsulatus) increased PUFA concentration and reduced cholesterol level in chickens [8-11]. However, unsaturated fatty acids (UFA) are more sensitive to oxidation than saturated fatty acids (SFA) and particularly vulnerable to peroxidative attack [12]. Several studies have suggested that increased PUFA 
of meat could be the result of protective effect of dietary antioxidants, since these antioxidants act as electron donors to provide electrons for reduction of some UFA $[5,13,14]$.

During the past decade, some studies have supported the potential reduction of oxidative stress of probiotics, such as Lactobacillus and Bifidobacterium [15-18]. Nevertheless, Clostridium butyricum can produce endospores and short-chain fatty acids, which has the ability to survive at lower $\mathrm{pH}$, relatively higher bile concentrations and temperature compared with Lactobacillus and Bifidobacterium and has been used in a wide range of human and veterinary intestinal diseases as one important symbiotic bacteria [19-22]. To our knowledge, information is lacking on the effects of $C$. butyricum on antioxidant properties and fatty acid composition of broilers. It is now hypothesized that $C$. butyricum might increase PUFA concentration of meat through improving antioxidant activity in broiler chicks. Therefore, the objectives of this study were to assess the effects of $C$. butyricum on antioxidant properties, meat quality and fatty acid composition of broiler chicks.

\section{Methods}

\section{Chicks, diets, and experimental design}

All experimental procedures were approved by the China Agricultural University Animal Care and Use Committee (Beijing, China). A total of 320 one-day-old Arbor Acres male broilers (Huadu Broiler Breeding Corporation, Beijing, China) were randomly allotted to one of five treatments of eight replicate cages with eight birds per cage in a completely randomized design for 42 days. Chicks were housed in a electrically heated, thermostatically controlled room with feeders, nipple drinker and steel cages, and standard conditions of temperature, humidity, and ventilation were provided for the entire experimental period. Feed and tap water were available ad libitum. The basal corn-soybean meal diets were formulated to meet or exceed the National Research Council (1994) [23] requirements of broilers for all nutrients (Table 1). Dietary treatments were as follows: basal diet (control), the basal diet supplemented with $2.5 \times 10^{8} \mathrm{cfu}$ of C. butyricum $/ \mathrm{kg}$ (CB1), $5 \times 10^{8} \mathrm{cfu}$ of C. butyricum $/ \mathrm{kg}$ (CB2), $1 \times 10^{9}$ cfu of C. butyricum $/ \mathrm{kg}$ (CB3), and $150 \mathrm{mg}$ of aureomycin $/ \mathrm{kg}$ (antibiotic). The strain of C. butyricum used in this study was C. butyricum CGMCC 8187 (China General Microbiological Culture Collection Center, Beijing, China).

\section{Sample collections and analysis}

At 21 days of age, only blood samples were taken from the wing vein of eight birds (one bird per cage) of each treatment and centrifuged at $3600 \times \mathrm{g}$ for $10 \mathrm{~min}$ at $4{ }^{\circ} \mathrm{C}$, serum was collected and stored at $-20^{\circ} \mathrm{C}$ until analysis.
Table 1 Composition of the basal diets for broilers (as-fed basis)

\begin{tabular}{|c|c|c|}
\hline Item (\% unless noted) & $\begin{array}{l}\text { Starter (1 to } \\
21 \text { days) }\end{array}$ & $\begin{array}{l}\text { Grower (22 to } \\
42 \text { days) }\end{array}$ \\
\hline \multicolumn{3}{|l|}{ Ingredient } \\
\hline Corn & 53.33 & 60.87 \\
\hline Soybean meal & 38.75 & 32.04 \\
\hline Soy oil & 3.70 & 3.26 \\
\hline Calcium monohydrogen phosphate & 1.98 & 1.69 \\
\hline Ground limestone & 1.05 & 1.08 \\
\hline Salt & 0.35 & 0.35 \\
\hline DL-Met & 0.18 & 0.12 \\
\hline Lysine & 0.04 & 0.02 \\
\hline Choline chloride (50\%) & 0.30 & 0.25 \\
\hline Mineral premix ${ }^{a}$ & 0.30 & 0.30 \\
\hline Vitamin premix ${ }^{b}$ & 0.02 & 0.02 \\
\hline \multicolumn{3}{|l|}{ Calculated nutrient compositon } \\
\hline $\mathrm{ME}, \mathrm{Mcal} / \mathrm{kg}$ & 2.95 & 3.00 \\
\hline $\mathrm{CP}$ & 21.00 & 19.00 \\
\hline Lysine & 1.15 & 1.00 \\
\hline Methionine & 0.50 & 0.40 \\
\hline Calcium & 0.98 & 0.90 \\
\hline Nonphytate phosphorus & 0.45 & 0.40 \\
\hline
\end{tabular}

${ }^{a}$ Supplied per kilogram of diet: Mn, 100 mg; Fe, 80 mg; Zn, 75 mg; $\mathrm{Cu}, 8 \mathrm{mg}$; Se, $0.15 \mathrm{mg}$; l, $0.35 \mathrm{mg}$.

bSupplied per kilogram of diet: vitamin A, $12500 \mathrm{IU}$; cholecalciferol, $2500 \mathrm{IU}$; vitamin E, $30 \mathrm{IU}$; vitamin $\mathrm{K}_{3}, 2.65 \mathrm{mg}$; thiamin, $2 \mathrm{mg}$; riboflavin, $6 \mathrm{mg}$; pantothenic acid, $12 \mathrm{mg}$; vitamin $\mathrm{B}_{12}, 0.025 \mathrm{mg}$; niacin, $50 \mathrm{mg}$; biotin, $0.0325 \mathrm{mg}$; folic acid, $1.25 \mathrm{mg}$.

At 42 days of age, eight chicks (one bird from each replicate cage) were weighed and chosen from each treatment based on average body weight within the pen following a 12-h fast. Blood samples were taken in the same way of the above-mentioned method. Then the birds were slaughtered and scalded in a hot water bath $\left(60^{\circ} \mathrm{C}\right.$ for $\left.45 \mathrm{~s}\right)$ and the feathers removed mechanically after bleeding. The weight of carcass was measured after defeathering to determine the dressing percentage. Then abdominal fat (leaf fat surrounding the cloaca and abdominal fat surrounding the gizzard) was collected and weighed. The heads, feet, and organs, except the lungs and kidneys were removed and weighted to determine the percentage of eviscerated yield. The breast and thigh muscles were removed and weighed to determine the percentages of breast and leg muscle. They were then divided into two parts respectively: one was quickly frozen at $-20^{\circ} \mathrm{C}$ for later determination of fatty acid composition, and another was used to measure meat color and $\mathrm{pH}$ value. Dressing, eviscerated yield and abdominal fat percentages were calculated by dividing these traits by final live weight after fasting. The percentages 
of breast muscle and thigh muscle were calculated as a percentage of eviscerated carcass weight.

\section{Meat quality}

Meat color was measured on 3 points of every meat at $45 \mathrm{~min}$ after slaughter by a spectrocolorimeter (model WSC-S, Shanghai Shenguang Ltd., Shanghai, China) according to the CIE $L^{*} a^{*} b^{*}$ color system (where $L^{*}$ measures relative lightness, $\mathrm{a}^{*}$ measures relative redness, and $b^{*}$ measures relative yellowness). The $\mathrm{pH}$ values of the breast and thigh muscles at a depth of $2.5 \mathrm{~cm}$ below the surface were measured at $45 \mathrm{~min}\left(\mathrm{pH}_{45 \mathrm{~min}}\right.$, initial $\left.\mathrm{pH}\right)$ and $24 \mathrm{~h}\left(\mathrm{pH}_{24 \mathrm{~h}}\right.$, ultimate $\left.\mathrm{pH}\right)$ postmortem using a Testo 205 pH meter (Testo AG, Lenzkirch, Germany) equipped with an insertion electrode. Three measurement values of $\mathrm{pH}_{45 \text { min }}$ and $\mathrm{pH}_{24 \mathrm{~h}}$ were recorded and averaged for each breast and thigh muscle.

\section{Assay of antioxidant indices}

The activities of superoxide dismutase (SOD), glutathione S-transferase (GST) and glutathione peroxidase (GPX), concentrations of glutathione (GSH) and malondialdehyde (MDA) in liver and serum were measured using SOD, GST, GPX, GSH and MDA assay kits (Nanjing Jiancheng Bioengineering Institute, Nanjing, China) according to the manufacture's protocols, respectively.

\section{Determination of serum biochemical parameters}

Serum cholesterol, triglyceride (TG), high-density lipoprotein cholesterol (HDL-C), and low-density lipoprotein cholesterol (LDL-C) were measured with the commercial kits (Baiding Biological Engineering Co., Ltd., Beijing, China) and an automatic biochemistry analyzer TBA120FR (Toshiba Medical Systems Co., Tokyo, Japan). All the procedures were carried out according to the manufacturers' instructions.

\section{Fatty acid analysis}

Fatty acid composition of breast and thigh muscles were determined by gas chromatography. The total lipids were extracted following the chloroform-methanol procedure of Folch et al. [24]. Total lipid extracts were transmethylated into fatty acid methyl esters using $\mathrm{KOH}$ in methanol and $14 \%$ methanolic boron triflouride and separated by using an HP 6890 gas chromatograph equipped with a flameionization detector and a DB-23 capillary column (internal diameter $0.25 \mathrm{~mm}$, length $60 \mathrm{~m}$, film thickness $0.25 \mu \mathrm{m}$; J\&W Scientific, Folsom, CA, USA). Injector and detector temperatures were $250^{\circ} \mathrm{C}$ and $280^{\circ} \mathrm{C}$, respectively. Nitrogen was used as the carrier gas at the flow rate of $1 \mathrm{~mL} / \mathrm{min}$. The oven temperature was $180^{\circ} \mathrm{C}$ held for $10 \mathrm{~min}$, increased to $220^{\circ} \mathrm{C}$ at $4^{\circ} \mathrm{C} / \mathrm{min}$ and held for $15 \mathrm{~min}$, then to $250^{\circ} \mathrm{C}$ at $3^{\circ} \mathrm{C} / \mathrm{min}$ and held for $30 \mathrm{~min}$. The fatty acids were identified by comparison of their retention times with those of standards and concentrations were expressed as milligram per $1 \mathrm{~g}$ of muscle.

\section{Statistical analyses}

Data from the experiment was analyzed by one-way ANOVA with the general liner model procedure of SAS (release 8.1, SAS Institute Inc., Cary, NC). Cage was the experimental unit. The $P<0.05$ was considered to be statistically significant. Differences among means were tested by the least significant difference method.

\section{Results}

\section{Antioxidant indices}

Broilers fed either CB2 or CB3 diet had greater $(P<0.05)$ SOD activity in the liver than those in the control group (Table 2), but no differences $(P<0.05)$ in SOD activity were found among the control group, CB1 group and antibiotic group. However, the addition of C. butyricum significantly decreased $(P<0.05)$ MDA concentration in the liver compared with the control. No differences in GST and GPX activities, and GSH concentration in liver were detected $(P>0.05)$ among all the treatments.

The GSH concentration of serum was higher $(P<0.05)$ in the chicks fed both CB1 and CB2 diets in comparison with those fed the either CB3 or antibiotic diet (Table 2), and birds fed the CB2 diet had higher $(P<0.05) \mathrm{GSH}$ content than those in the control group. Nevertheless, birds fed the control, CB1 and CB2 diets had lower $(P<0.05)$ MDA concentration of serum than those in the antibiotic group. No significant differences $(P>0.05)$ were observed in SOD, GST or GPX activities in serum among all the treatments.

\section{Serum biochemical parameters}

Both cholesterol and HDL-C concentrations of serum at 21 days of age were lower $(P<0.05)$ in the chicks fed CB2 and CB3 diets compared with those fed the control diet (Table 3$)$, but no differences $(P>0.05)$ were found in TG and LDL-C contents of serum at 21 days of age among the 5 treatments. There were no differences in TG, HDL-C and LDL-C contents were detected $(P>0.05)$ among all the treatments, but broilers in the $C$. butyricum-supplemented groups had lower $(P<0.05)$ cholesterol concentration at 42 days of age than those in the control group.

\section{Carcass traits}

Broilers in the $C$. butyricum-supplemented groups had lower $(P<0.05)$ percentage of abdominal fat than those in the antibiotic group (Table 4); furthermore, broilers in the either CB1 or CB3 group had lower $(P<0.05)$ percentage of abdominal fat than those in the control group. However, broilers fed CB3 diet had higher $(P<0.05)$ breast muscle percentage than those in the control, $\mathrm{CB} 1$ 
Table 2 Effect of $C$. butyricum on antioxidant indices in liver and serum of broilers

\begin{tabular}{|c|c|c|c|c|c|c|c|}
\hline Item & Control & CB1 & CB2 & CB3 & Antibiotic & Pooled SE & $P$-value \\
\hline \multicolumn{8}{|l|}{$\overline{\text { Liver }^{a}}$} \\
\hline SOD (U/mg protein) & $195 c$ & $212 b c$ & $240 a$ & $226 a b$ & $210 b c$ & 6 & 0.0002 \\
\hline GST (U/mg protein) & 59.0 & 52.8 & 52.4 & 60.7 & 53.1 & 3.9 & 0.4546 \\
\hline GPX (U/mg protein) & 8.49 & 9.45 & 9.19 & 8.67 & 9.26 & 0.36 & 0.2836 \\
\hline GSH ( $\mu$ mol/g protein) & 10.09 & 9.39 & 10.32 & 9.39 & 9.36 & 0.50 & 0.5412 \\
\hline MDA (nmol/mg protein) & $1.02 \mathrm{a}$ & $0.88 \mathrm{bc}$ & $0.82 \mathrm{c}$ & $0.86 b c$ & $0.93 a b$ & 0.03 & 0.0014 \\
\hline \multicolumn{8}{|l|}{ Serum $^{a}$} \\
\hline $\mathrm{SOD}(\mathrm{U} / \mathrm{ml})$ & 118 & 110 & 128 & 113 & 107 & 9 & 0.5090 \\
\hline GST (U/ml) & 22.9 & 22.7 & 22.4 & 21.5 & 19.8 & 0.8 & 0.0680 \\
\hline GPX (U) & 785 & 797 & 786 & 867 & 890 & 46 & 0.4621 \\
\hline $\mathrm{GSH}(\mu \mathrm{mol} / \mathrm{L})$ & $29.9 b c$ & $32.5 \mathrm{ab}$ & $38.0 \mathrm{a}$ & $24.6 \mathrm{~cd}$ & $22.1 d$ & 2.7 & 0.0016 \\
\hline $\mathrm{MDA}(\mathrm{nmol} / \mathrm{ml})$ & $2.36 \mathrm{bc}$ & $2.37 b c$ & $2.24 c$ & $2.80 a b$ & $2.87 a$ & 0.16 & 0.0282 \\
\hline
\end{tabular}

Means with different letters within the same row differ $(P<0.05)$.

Control = basal diet; $C B 1=$ the basal diet supplemented with $2.5 \times 10^{8} \mathrm{cfu}$ of $C$. butyricum $/ \mathrm{kg} ; \mathrm{CB} 2=$ the basal diet supplemented with $5 \times 10^{8} \mathrm{cfu}$ of

C. butyricum $/ \mathrm{kg} ; \mathrm{CB} 3=$ the basal diet supplemented with $1 \times 10^{9} \mathrm{cfu}$ of $\mathrm{C}$. butyricum $/ \mathrm{kg} ;$ Antibiotic $=$ the basal diet supplemented with $150 \mathrm{mg}$ of aureomycin $/ \mathrm{kg}$.

$\mathrm{SOD}=$ superoxide dismutase; GST = glutathione S-transferase; GPX = glutathione peroxidase; GSH = glutathione; MDA = malondialdehyde.

${ }^{a}$ Each value represents the mean of 8 cages with one chick per cage $(n=8$ per treatment).

and antibiotic groups. No significant differences $(P>0.05)$ were observed in percentages of dressing, eviscerated yield and thigh muscle among all the treatments.

\section{Fatty acid composition}

There were significant differences $(P<0.05)$ in some fatty acid concentrations in the breast muscle amongst the treatments (Table 5). For SFA, broilers fed CB2 diet resulted in higher $(P<0.05)$ concentration of stearic acid (C18:0) than those in the control, CB1 and antibiotic groups, but no significant differences $(P>0.05)$ were observed in other SFA and total SFA contents among all the treatments. For monounsaturated fatty acids (MUFA), broilers fed either CB1or CB2 diet had higher $(P<0.05)$ concentration of gondoic acid $(C 20: 1 n-9)$ than those in the control group. Among PUFA, the addition of C. butyricum significantly affected $(P<0.05)$ the concentrations of eicosadienoic acid (C20:2n-6), dihomo-gammalinolenic acid (DGLA: C20:3n-6), eicosatrienoic acid (ETE: C20:3n-3), arachidonic acid (AA: C20:4n-6), eicosapentaenoic acid (EPA: C20:5n-3), docosahexaenoic acid (DHA: C22:6n-3), total PUFA and ratio of PUFA to SFA. Chicks fed CB2, CB3 and antibiotic diets had greater $(P<0.05)$ AA concentration than those in the control group. Birds fed either $\mathrm{CB} 1$ or $\mathrm{CB} 2$ diet had higher $(P<0.05)$ EPA concentration than those in the control group. In comparison with the control group, the $C$. butyricum-supplemented and antibiotic groups had higher $(P<0.05)$ DHA concentration. Moreover, birds in the CB2, CB3 and antibiotic groups had higher $(P<0.05)$

Table 3 Effect of C. butyricum on serum biochemical parameters of broilers

\begin{tabular}{|c|c|c|c|c|c|c|c|}
\hline Item & Control & CB1 & $\mathrm{CB} 2$ & CB3 & Antibiotic & Pooled SE & $P$-value \\
\hline \multicolumn{8}{|l|}{21 days $^{a}$} \\
\hline Total cholesterol (mM) & $3.78 \mathrm{a}$ & $3.51 \mathrm{abc}$ & $3.25 \mathrm{c}$ & $3.42 \mathrm{bc}$ & $3.65 a b$ & 0.1 & 0.0111 \\
\hline Triglyceride (mM) & 0.74 & 0.72 & 0.75 & 0.68 & 0.67 & 0.10 & 0.0111 \\
\hline High-density lipoprotein cholesterol (mM) & $2.35 \mathrm{a}$ & $2.28 \mathrm{ab}$ & $2.05 \mathrm{c}$ & $2.10 \mathrm{bc}$ & $2.23 a b c$ & 0.07 & 0.0233 \\
\hline Low-density lipoprotein cholesterol (mM) & 1.27 & 1.24 & 1.23 & 1.20 & 1.27 & 0.05 & 0.8976 \\
\hline \multicolumn{8}{|l|}{42 days $^{a}$} \\
\hline Total cholesterol (mM) & $3.37 a$ & $3.05 b$ & $2.96 b$ & $2.90 \mathrm{~b}$ & 3.09ab & 0.1 & 0.0287 \\
\hline Triglyceride (mM) & 0.41 & 0.37 & 0.30 & 0.32 & 0.36 & 0.03 & 0.1437 \\
\hline High-density lipoprotein cholesterol (mM) & 2.06 & 1.93 & 1.81 & 1.88 & 2.02 & 0.07 & 0.1216 \\
\hline Low-density lipoprotein cholesterol (mM) & 1.06 & 1.01 & 0.98 & 1.04 & 1.05 & 0.06 & 0.8519 \\
\hline
\end{tabular}

Means with different letters within the same row differ $(P<0.05)$.

Control = basal diet; $C B 1=$ the basal diet supplemented with $2.5 \times 10^{8} \mathrm{cfu}$ of $C$. butyricum $/ \mathrm{kg} ; \mathrm{CB} 2=$ the basal diet supplemented with $5 \times 10^{8} \mathrm{cfu}$ of C. butyricum $/ \mathrm{kg} ; \mathrm{CB} 3=$ the basal diet supplemented with $1 \times 10^{9} \mathrm{cfu}$ of $\mathrm{C}$. butyricum $/ \mathrm{kg}$; Antibiotic = the basal diet supplemented with $150 \mathrm{mg}$ of aureomycin/kg. aEach value represents the mean of 8 cages with one chick per cage ( $n=8$ per treatment). 
Table 4 Effect of $C$. butyricum on carcass traits of broilers

\begin{tabular}{llllllll}
\hline Item $^{\mathbf{a}, \mathbf{b}}$ & Control & CB1 & CB2 & CB3 & Antibiotic & Pooled SE & P-value \\
\hline Dressing (\%) & 90.5 & 89.3 & 90.0 & 89.7 & 88.8 & 0.4 & 0.0764 \\
Abdominal fat (\%) & $1.50 \mathrm{ab}$ & $1.23 \mathrm{c}$ & $1.30 \mathrm{bc}$ & $1.27 \mathrm{c}$ & $1.57 \mathrm{a}$ & 0.08 & 0.0339 \\
Eviscerated yield (\%) & 71.2 & 71.5 & 71.8 & 72.1 & 72.0 & 0.6 & 0.8087 \\
Breast muscle (\%) & $26.8 \mathrm{~b}$ & $27.8 \mathrm{~b}$ & $28.0 \mathrm{ab}$ & $29.9 \mathrm{a}$ & $27.5 \mathrm{~b}$ & 0.7 & 0.0367 \\
Thigh muscle (\%) & 22.5 & 22.0 & 21.8 & 22.3 & 21.2 & 0.5 & 0.4417 \\
\hline
\end{tabular}

Means with different letters within the same row differ $(P<0.05)$.

Control = basal diet; $C B 1=$ the basal diet supplemented with $2.5 \times 10^{8} \mathrm{cfu}$ of $\mathrm{C}$. butyricum $/ \mathrm{kg} ; \mathrm{CB} 2=$ the basal diet supplemented with $5 \times 10^{8} \mathrm{cfu}$ of

C. butyricum $/ \mathrm{kg} ; \mathrm{CB} 3=$ the basal diet supplemented with $1 \times 10^{9} \mathrm{cfu}$ of $\mathrm{C}$. butyricum $/ \mathrm{kg}$; Antibiotic = the basal diet supplemented with $150 \mathrm{mg}$ of aureomycin/kg.

${ }^{a}$ Each value represents the mean of 8 cages with one chick per cage $(n=8$ per treatment).

${ }^{b}$ Dressing, abdominal fat and eviscerated yield percentages were calculated by dividing these traits by final live weight after fasting. The percentages of breast muscle and thigh muscle were calculated as a percentage of eviscerated carcass weight.

Table 5 Effect of C. butyricum on fatty acid contents ( $\mathrm{mg} / \mathrm{g}$ of dried meat) of breast meat

\begin{tabular}{|c|c|c|c|c|c|c|c|}
\hline Item $^{a}$ & Control & CB1 & CB2 & CB3 & Antibiotic & Pooled SE & $P$-value \\
\hline C14:0 & 0.155 & 0.157 & 0.165 & 0.189 & 0.168 & 0.018 & 0.6914 \\
\hline C15:0 & 0.020 & 0.027 & 0.016 & 0.034 & 0.018 & 0.006 & 0.2711 \\
\hline C16:0 & 8.18 & 9.03 & 10.68 & 9.34 & 9.31 & 0.85 & 0.3929 \\
\hline C17:0 & 0.041 & 0.049 & 0.048 & 0.065 & 0.041 & 0.006 & 0.0649 \\
\hline C18:0 & $3.66 b$ & $4.29 b$ & $5.39 a$ & 4.47ab & $4.31 b$ & 0.32 & 0.0166 \\
\hline C20:0 & 0.064 & 0.132 & 0.106 & 0.085 & 0.083 & 0.020 & 0.2094 \\
\hline$\Sigma S F A$ & 12.12 & 13.69 & 16.41 & 14.18 & 13.93 & 1.18 & 0.1935 \\
\hline C14:1 & 0.017 & 0.016 & 0.004 & 0.016 & 0.015 & 0.007 & 0.6861 \\
\hline $\mathrm{C} 16: 1 \mathrm{C}$ & 1.09 & 1.05 & 1.22 & 1.03 & 1.07 & 0.17 & 0.9427 \\
\hline$C 18: 1 t$ & 0.169 & 0.166 & 0.209 & 0.210 & 0.163 & 0.020 & 0.2673 \\
\hline C18:1C & 9.01 & 10.50 & 13.31 & 11.39 & 10.76 & 1.35 & 0.3024 \\
\hline C20:1n-9 & $0.112 c$ & $0.190 a b$ & $0.209 a$ & $0.152 a b c$ & $0.145 b c$ & 0.021 & 0.0277 \\
\hline$C 22: 1 n-9$ & 0.018 & 0.051 & 0.042 & 0.043 & 0.047 & 0.009 & 0.1230 \\
\hline$\Sigma M U F A$ & 10.42 & 11.97 & 14.99 & 12.84 & 12.20 & 1.54 & 0.3710 \\
\hline$C 18: 2 t-9, t-12$ & 0.008 & 0.032 & 0.020 & 0.016 & 0.006 & 0.007 & 0.0917 \\
\hline C18:2C & 7.94 & 9.81 & 12.77 & 10.69 & 10.64 & 1.05 & 0.0552 \\
\hline C18:3n-6 & 0.022 & 0.031 & 0.013 & 0.023 & 0.021 & 0.006 & 0.3856 \\
\hline C18:3n-3 & 0.456 & 0.606 & 0.769 & 0.676 & 0.693 & 0.089 & 0.1965 \\
\hline$C 20: 2 n-6$ & $0.233 b$ & $0.374 a$ & $0.424 a$ & $0.327 a b$ & $0.341 a$ & 0.036 & 0.0106 \\
\hline$C 20: 3 n-6$ & $0.070 c$ & $0.130 \mathrm{~b}$ & $0.195 a$ & $0.110 \mathrm{~b}$ & $0.100 b c$ & 0.011 & $<.0001$ \\
\hline$C 20: 3 n-3$ & $0.415 c$ & $0.573 b$ & $0.725 a$ & $0.512 b c$ & $0.540 \mathrm{bc}$ & 0.048 & 0.0016 \\
\hline$C 20: 4 n-6$ & $1.20 \mathrm{c}$ & $1.80 \mathrm{bc}$ & $3.35 a$ & $2.24 b$ & $2.22 \mathrm{~b}$ & 0.21 & $<.0001$ \\
\hline$C 20: 5 n-3$ & $0.100 c$ & $0.143 a b$ & $0.181 a$ & $0.123 b c$ & $0.123 b c$ & 0.014 & 0.0047 \\
\hline$C 22: 6 n-3$ & $0.201 b$ & $0.341 a$ & $0.366 a$ & $0.301 a$ & $0.293 a$ & 0.026 & 0.0010 \\
\hline$\Sigma$ PUFA & $10.60 c$ & $13.86 \mathrm{bc}$ & $18.04 a$ & 15.67ab & 14.98ab & 1.37 & 0.0103 \\
\hline PUFA/SFA & $0.87 d$ & $1.01 \mathrm{C}$ & $1.14 a$ & $1.07 \mathrm{bc}$ & $1.08 a b$ & 0.02 & $<.0001$ \\
\hline
\end{tabular}

Means with different letters within the same row differ $(P<0.05)$

Control = basal diet; $C B 1=$ the basal diet supplemented with $2.5 \times 10^{8} \mathrm{cfu}$ of $\mathrm{C}$. butyricum $/ \mathrm{kg} ; \mathrm{CB} 2=$ the basal diet supplemented with $5 \times 10^{8}$ cfu of

C. butyricum $/ \mathrm{kg} ; \mathrm{CB} 3=$ the basal diet supplemented with $1 \times 10^{9} \mathrm{cfu}$ of $C$. butyricum $/ \mathrm{kg} ;$ Antibiotic = the basal diet supplemented with $150 \mathrm{mg}$ of aureomycin $/ \mathrm{kg}$.

$c=c i s ; t=$ trans.

${ }^{a}$ Each value represents the mean of 8 cages with one chick per cage $(n=8$ per treatment). 
total PUFA concentration than those in the control group, and birds in the C. butyricum-supplemented and antibiotic groups had higher $(P<0.05)$ ratio of PUFA to SFA than those in the control group. Nevertheless, no significant differences $(P>0.05)$ were observed in other UFA in breast muscle among all the treatments.

The trans, trans-linoleic acid (C18:2 $t-9, t$-12), DGLA (C20:3n-6), ETE (C20:3n-3) and EPA (C20:5n-3) contents in thigh muscle were significantly affected $(P<0.05)$ by dietary treatments (Table 6). Birds fed control and $C$. butyricum-supplemented diets had greater $(P<0.05)$ trans, trans-linoleic acid and DGLA concentrations than those in the antibiotic group, and birds fed control, CB1 and CB2 diets had greater $(P<0.05)$ ETE and EPA concentrations than those in the antibiotic group. However, no significant differences $(P>0.05)$ in other fatty acids, total SFA, total MUFA, total PUFA and the ratio of PUFA to SFA in the thigh muscle were detected $(P>0.05)$ among all the treatments.

\section{Meat quality}

Birds fed either CB1 or antibiotic diet had greater $(P<0.05)$ $\mathrm{pH}_{45 \min }$ value in the breast than those in the control or CB2 group (Table 7), whereas birds fed CB1, CB2 or antibiotic diet had greater $(P<0.05) \mathrm{pH}_{45 \min }$ value in the thigh muscle than those in the control group. However, no differences $(P>0.05)$ in $\mathrm{pH}_{24 \mathrm{~h}}$ values of breast and thigh muscles were detected among all the treatments.

Broilers in the either CB1 or CB2 group had lower $(P<0.05) b^{*}$ value of breast than those in the antibiotic group (Table 7). However, no significant differences $(P>0.05)$ in $\mathrm{L}^{*}$ and $\mathrm{a}^{*}$ values in the breast muscle and $\mathrm{L}^{*}$,

Table 6 Effect of C. butyricum on fatty acid contents ( $\mathrm{mg} / \mathrm{g}$ of dried meat) of thigh meat

\begin{tabular}{|c|c|c|c|c|c|c|c|}
\hline Item $^{a}$ & Control & CB1 & CB2 & CB3 & Antibiotic & Pooled SE & $P$-value \\
\hline C14:0 & 0.317 & 0.298 & 0.282 & 0.277 & 0.273 & 0.032 & 0.8660 \\
\hline C15:0 & 0.059 & 0.053 & 0.053 & 0.052 & 0.052 & 0.006 & 0.8735 \\
\hline C16:0 & 14.89 & 13.97 & 14.00 & 12.74 & 12.36 & 1.49 & 0.7518 \\
\hline C17:0 & 0.118 & 0.137 & 0.101 & 0.169 & 0.087 & 0.032 & 0.4256 \\
\hline C18:0 & 7.02 & 6.43 & 6.96 & 6.53 & 5.80 & 0.46 & 0.3515 \\
\hline C20:0 & 0.129 & 0.116 & 0.140 & 0.109 & 0.104 & 0.018 & 0.5969 \\
\hline$\Sigma S F A$ & 22.53 & 21.00 & 21.54 & 19.88 & 18.67 & 1.96 & 0.6780 \\
\hline C14:1 & 0.051 & 0.051 & 0.050 & 0.036 & 0.040 & 0.013 & 0.8877 \\
\hline C16:1C & 2.43 & 2.20 & 2.17 & 1.77 & 1.87 & 0.36 & 0.7030 \\
\hline C17:1 & 0.027 & 0.025 & 0.022 & 0.017 & 0.007 & 0.005 & 0.1083 \\
\hline$C 18: 1 t$ & 0.230 & 0.200 & 0.223 & 0.194 & 0.321 & 0.045 & 0.2993 \\
\hline C18:1C & 18.68 & 16.47 & 17.49 & 15.79 & 14.96 & 2.40 & 0.8291 \\
\hline C20:1n-9 & 0.233 & 0.200 & 0.264 & 0.250 & 0.173 & 0.027 & 0.1286 \\
\hline$C 22: 1 n-9$ & 0.034 & 0.041 & 0.045 & 0.045 & 0.033 & 0.007 & 0.5814 \\
\hline$\Sigma M U F A$ & 21.68 & 19.18 & 20.27 & 18.10 & 17.40 & 2.80 & 0.8268 \\
\hline$C 18: 2 t-9, t-12$ & $0.035 a$ & $0.033 a$ & $0.046 a$ & $0.038 a$ & $0.010 \mathrm{~b}$ & 0.006 & 0.0034 \\
\hline $\mathrm{C} 18: 2 \mathrm{C}$ & 16.41 & 15.85 & 17.28 & 15.76 & 14.99 & 1.81 & 0.9246 \\
\hline C18:3n-6 & 0.057 & 0.043 & 0.073 & 0.046 & 0.041 & 0.011 & 0.2616 \\
\hline$C 18: 3 n-3$ & 0.990 & 0.993 & 1.078 & 0.960 & 0.982 & 0.153 & 0.9857 \\
\hline$C 20: 2 n-6$ & 0.358 & 0.380 & 0.373 & 0.362 & 0.287 & 0.041 & 0.5251 \\
\hline$C 20: 3 n-6$ & $0.131 b$ & $0.140 a b$ & $0.151 \mathrm{ab}$ & $0.157 a$ & $0.101 c$ & 0.008 & 0.0003 \\
\hline$C 20: 3 n-3$ & $0.592 \mathrm{a}$ & $0.574 a$ & $0.636 a$ & $0.561 \mathrm{ab}$ & $0.463 b$ & 0.036 & 0.0248 \\
\hline$C 20: 4 n-6$ & 2.25 & 2.09 & 2.36 & 2.24 & 1.97 & 0.14 & 0.3483 \\
\hline$C 20: 5 n-3$ & $0.128 a$ & $0.122 a$ & $0.136 a$ & $0.115 a b$ & $0.093 b$ & 0.009 & 0.0327 \\
\hline$C 22: 6 n-3$ & 0.366 & 0.385 & 0.390 & 0.377 & 0.302 & 0.032 & 0.3040 \\
\hline$\sum$ PUFA & 21.32 & 20.61 & 22.53 & 20.61 & 19.24 & 2.13 & 0.8650 \\
\hline PUFA/SFA & 0.95 & 0.98 & 1.04 & 1.02 & 1.04 & 0.03 & 0.1390 \\
\hline
\end{tabular}

Means with different letters within the same row differ $(P<0.05)$.

Control = basal diet; $\mathrm{CB} 1=$ the basal diet supplemented with $2.5 \times 10^{8} \mathrm{cfu}$ of $C$. butyricum $/ \mathrm{kg} ; \mathrm{CB} 2=$ the basal diet supplemented with $5 \times 10^{8} \mathrm{cfu}$ of

C. butyricum $/ \mathrm{kg} ; \mathrm{CB3}=$ the basal diet supplemented with $1 \times 10^{9} \mathrm{cfu}$ of $C$. butyricum $/ \mathrm{kg} ;$ Antibiotic $=$ the basal diet supplemented with $150 \mathrm{mg}$ of aureomycin $/ \mathrm{kg}$. $c=c i s ; t=$ trans.

${ }^{a}$ Each value represents the mean of 8 cages with one chick per cage ( $n=8$ per treatment). 
Table 7 Effect of $C$. butyricum on meat quality of broilers

\begin{tabular}{|c|c|c|c|c|c|c|c|}
\hline Item & Control & CB1 & CB2 & CB3 & Antibiotic & Pooled SE & $P$-value \\
\hline \multicolumn{8}{|c|}{ Breast muscle $^{a}$} \\
\hline Lightness & 56.8 & 54.0 & 57.5 & 59.4 & 55.3 & 1.6 & 0.1562 \\
\hline Redness & 11.1 & 11.1 & 10.6 & 10.0 & 10.4 & 0.7 & 0.7995 \\
\hline Yellowness & $12.2 \mathrm{ab}$ & $11.1 b$ & $11.1 b$ & $12.8 a b$ & $13.9 \mathrm{a}$ & 0.7 & 0.0240 \\
\hline $\mathrm{pH}_{45 \min }$ & $6.19 b$ & $6.49 a$ & $6.12 b$ & $6.27 \mathrm{ab}$ & $6.48 a$ & 0.09 & 0.0119 \\
\hline $\mathrm{pH}_{24 h}$ & 5.98 & 5.96 & 6.04 & 6.06 & 6.01 & 0.03 & 0.2033 \\
\hline \multicolumn{8}{|c|}{ Thigh muscle } \\
\hline Lightness & 59.3 & 58.6 & 60.2 & 58.2 & 58.0 & 1.3 & 0.7344 \\
\hline Redness & 14.0 & 14.5 & 12.4 & 13.1 & 13.0 & 0.6 & 0.1742 \\
\hline Yellowness & 10.3 & 9.8 & 9.7 & 12.0 & 12.9 & 1.0 & 0.1027 \\
\hline $\mathrm{pH}_{45 \min }$ & $6.41 c$ & $6.60 a$ & $6.53 a b$ & $6.45 b c$ & $6.55 \mathrm{ab}$ & 0.04 & 0.0049 \\
\hline $\mathrm{pH}_{24 h}$ & 6.58 & 6.69 & 6.67 & 6.61 & 6.78 & 0.08 & 0.3774 \\
\hline
\end{tabular}

Means with different letters within the same row differ $(P<0.05)$.

Control = basal diet; $C B 1=$ the basal diet supplemented with $2.5 \times 10^{8} \mathrm{cfu}$ C. butyricum $/ \mathrm{kg} ; \mathrm{CB} 2=$ the basal diet supplemented with $5 \times 10^{8}$ cfu C. butyricum $/ \mathrm{kg}$; $\mathrm{CB} 3=$ the basal diet supplemented with $1 \times 10^{9} \mathrm{cfu}$ C. butyricum $/ \mathrm{kg}$; Antibiotic = the basal diet supplemented with $150 \mathrm{mg}$ of aureomycin $/ \mathrm{kg}$. $\mathrm{pH}_{45 \text { min }}$ ( 45 min postmortem); $\mathrm{pH}_{24 \mathrm{~h}}$ ( $24 \mathrm{~h}$ postmortem).

${ }^{\mathrm{a}}$ Each value represents the mean of 8 cages with one chick per cage ( $\mathrm{n}=8$ per treatment).

$\mathrm{a}^{*}$ and $\mathrm{b}^{*}$ values in the thigh muscle were detected among all the treatments.

\section{Discussion}

In recent years, consumers are becoming increasingly aware of the nutritional quality and healthy benefits of the food they consume. It is widely acknowledged that cholesterol content and fatty acid composition in poultry products are closely related to the occurrence of cardiovascular heart diseases [25]. Therefore, much attention has been paid toward the modulation of poultry products to decrease the risk of cardiovascular disease by improving the properties of carcasses and meat quality [5]. The present study showed that deposition of abdominal fat and serum cholesterol content in broiler chicks could be decreased while breast muscle yield and some PUFA concentrations of breast and thigh muscles could be increased by supplementing C. butyricum in the diet.

Some experiments were conducted to investigate the effects of probiotics on carcass traits and meat quality in animals. Suo et al. [26] found that L. plantarum ZJ316 had probiotic effects on improving pork quality, $\mathrm{pH}_{45 \mathrm{~min}}$, hardness, stickiness, chewiness, gumminess and restoring force were all improved in Lactobacillus-treated pigs. Endo and Nakano [27] reported that dietary supplementation of probiotics (Bacillus, Lactobacillus, Streptococcus, Clostridium, Saccharomyces, and Candida spp.) enhanced the characteristics of carcass and meat quality in broilers. Results from the current study demonstrated that the addition of $C$. butyricum significantly influenced percentages of abdominal fat and breast muscle, $\mathrm{pH}_{45 \mathrm{~min}}$ and $\mathrm{b}^{*}$ values. Supplementation of C. butyricum resulted in better body composition with higher breast meat yield and lower abdominal fat percentage in broilers, which could be beneficial for poultry production.

The present data demonstrate that cholesterol and HDL-C contents of serum in broilers were decreased by C. butyricum supplementation at a level of either $5 \times 10^{8}$ or $1 \times 10^{9} \mathrm{cfu} / \mathrm{kg}$ of diet. Similar results were observed in the previous studies, indicating that supplemental $C$. butyricum decreased plasma and hepatic cholesterol levels and enhanced bile acid excretion in cholesterol-fed rats [28-30]. Furthermore, some studies have shown that Lactobacillus or Bacillus reduced cholesterol concentration in serum [31,32], in egg yolk $[33,10]$, as well as in liver and carcass [9] of broiler chickens. The mechanisms for the cholesterol-lowering action of probiotic bacteria remains unclear, but it has been suggested that the effect may be attributed to binding of cholesterol to the bacterial cell wall, retarding cholesterol synthesis or increasing degradation of cholesterol by gut bacterial enzymes $[9,34,35]$. In addition, the development of adipose tissue depends on the availability of serum lipids which are principal substrates in lipid metabolism [36], suggesting that the decreased abdominal fat content evoked by $C$. butyricum supplementation as observed in this study might be associated with reduced serum lipids.

Fatty acid profile in animal products depends strongly on the fatty acid composition of the diet. Human nutritionists are recommending a higher intake of PUFA, which have a wide range of biological roles and are believed to be beneficial for human health $[2,4]$. In the present study, dietary supplementation of $C$. butyricum to broilers increased some PUFA contents and the ratio of PUFA to SFA in the breast and thigh muscles, especially for AA, EPA and 
DHA, which were supported by the study of Yang et al. [7], who reported that dietary C. butyricum increased AA and total n-3 fatty acid contents in breast meat of chickens. Moreover, the similar phenomenon was also reported in other studies [11,32], in which increased levels of AA and UFA/SFA ratio were found in the liver and meat of broilers supplemented with other probiotics (Lactobacillus and Rhodobacter capsulatus). These above results can be attractive to the consumers as high ratio of PUFA to SFA has a positive health benefit for humans, mainly in protection against cardiovascular disease [3].

The mechanisms by which dietary C. butyricum regulates PUFA contents of meat are still unclear. Notwithstanding, it is well recognized that probiotics can cause a positive effect on animal health through administering the digestive tract and affecting PUFA digestion and absorption processes in the gastrointestinal tract $[7,37]$. Recently, some studies have suggested that increased PUFA concentrations in meat could be on account of the protective role of dietary antioxidants [5,14,38]. Higher level of antioxidative enzymes will lead to reduction of the rate of lipid peroxidation, which means reduction of the rate of PUFA degradation by peroxidation [14]. Results from the present study showed that $C$. butyricum could inhibit both liver and blood lipid oxidation (MDA production) in broiler chicks, therefore protecting the peroxidation of oxidative-labile PUFA of meat. During the past decade, several studies have supported the potential reduction of oxidative stress of probiotics, such as Lactobacillus and Bifidobacterium [15-18]. The current study found that dietary supplementation of $C$. butyricum increased hepatic SOD activity and serum GSH content whereas decreased MDA concentration in both liver and serum of broilers. These results were supported by a recent study [39], which indicated that $C$. butyricum-treated rats showed remarkable induction of nuclear factor erythoid 2-related factor 2 (Nrf2) and its targeted antioxidative enzymes and suppressed hepatic oxidative stress. Moreover, C. butyricum can produce both butyric acid and $\mathrm{H}_{2}[40,41]$, the effects of butyrate on colonic mucosal health and antioxidative activity have been widely studied [42,43]; and recent studies have revealed that molecular $\mathrm{H}_{2}$ mediates beneficial effects in different systems as an optimal antioxidant agent by selectively scavenging free hydroxyl radicals $(\cdot \mathrm{OH})$ [44]. Thus, C. butyricum exert antioxidant properties may be partially attributed to the benefit effects of butyrate and $\mathrm{H}_{2}$ on reduction of oxidative stress. This could be supported by a previous study, which demonstrated that dietary sodium butyrate alleviated the oxidative stress induced by corticosterone exposure and increased AA contents in breast muscle of broilers [36]. Furthermore, other studies have indicated that some probiotic strains exert antioxidant activity and may be useful in reducing systemic oxidative stress through either stimulating the immune system reduces inflammation or increasing the amount of probiotics while inhibiting intestinal pathogens reduces inflammation and its associated oxidative injury $[16,17,20,39]$. However, the exact mechanisms need to be further studied.

\section{Conclusions}

In summary, the results from the current study indicate that supplementation of $C$. butyricum promotes antioxidant status in liver and serum, decreases cholesterol and HDL-C concentrations in serum, and improves meat quality and fatty acid composition of broiler birds. Consumption of such a meat product may be beneficial to human health. The increased concentrations of PUFA observed in muscle of broilers fed a diet supplemented with $C$. butyricum may be as a result of the enhancement of antioxidant defenses in the host and deserves further investigation.

\section{Competing interests}

The authors declare that they have no competing interests.

\section{Authors' contributions}

$\mathrm{XL}, \mathrm{RW}$ and RZ designed the study. XL, RW, GM, LZ and ZZ performed experiments and analyzed the data. $\mathrm{XL}$ and RW drafted the manuscript, and $\mathrm{RW}$ and $\mathrm{RZ}$ reviewed the manuscript. All authors read and approved the final manuscript.

\section{Acknowledgements}

This study was financed by the National Key Technology R \& D Program during the Twelfth Five-year Plan Period (Project No. 2011BAD26B02 and 2011BAD26B04).

Received: 24 January 2015 Accepted: 16 April 2015

Published online: 22 April 2015

References

1. Parra V, Petrón MJ, Martín L, Broncano JM, Timón ML. Modification of the fat composition of the Iberian pig using Bacillus licheniformis and Bacillus subtilis. Eur J Lipid Sci Technol. 2010;112(7):720-6. doi:10.1002/ejlt.200900155.

2. Raes K, De Smet S, Demeyer D. Effect of dietary fatty acids on incorporation of long chain polyunsaturated fatty acids and conjugated linoleic acid in lamb, beef and pork meat: a review. Anim Feed Sci Tech. 2004;113(1-4):199-221.

3. Cao Y, Lu L, Liang J, Liu M, Li X, Sun R et al. Omega-3 fatty acids and primary and secondary prevention of cardiovascular disease. Cell Biochem Biophys. 2014. doi:10.1007/s12013-014-0407-5

4. Woods VB, Fearon AM. Dietary sources of unsaturated fatty acids for animals and their transfer into meat, milk and eggs: A review. Livest Sci. 2009;126(1-3):1-20.

5. Kamboh AA, Zhu WY. Effect of increasing levels of bioflavonoids in broiler feed on plasma anti-oxidative potential, lipid metabolites, and fatty acid composition of meat. Poult Sci. 2013;92(2):454-61. doi:10.3382/ps.2012-02584.

6. Hulan HW, Ackman RG, Ratnayake WMN, Proudfoot FG. Omega-3 fatty acid levels and general performance of commercial broilers fed practical levels of redfish meal. Poult Sci. 1989;68(1):153-62.

7. Yang X, Zhang B, Guo Y, Jiao P, Long F. Effects of dietary lipids and Clostridium butyricum on fat deposition and meat quality of broiler chickens. Poult Sci. 2010;89(2):254-60. doi:10.3382/ps.2009-00234.

8. Herzallah S. Enrichment of conjugated linoleic acid (CLA) in hen eggs and broiler chickens meat by lactic acid bacteria. Br Poult Sci. 2013;54(6):747-52. doi:10.1080/00071668.2013.836734.

9. Kalavathy $\mathrm{R}$, Abdullah $\mathrm{N}$, Jalaludin S, Wong M, Ho YW. Effects of Lactobacillus feed supplementation on cholesterol, fat content and fatty acid composition of the liver, muscle and carcass of broiler chickens. Anim Res. 2006;55(1):77-82. doi:10.1051/animres:2005043. 
10. Ramasamy K, Abdullah N, Jalaludin S, Wong M, Ho YW. Effects of Lactobacillus cultures on performance of laying hens, and total cholesterol, lipid and fatty acid composition of egg yolk. J Sci Food Agric. 2009;89(3):482-6. doi:10.1002/jsfa.3477.

11. Salma U, Miah AG, Maki T, Nishimura M, Tsujii H. Effect of dietary Rhodobacter capsulatus on cholesterol concentration and fatty acid composition in broiler meat. Poult Sci. 2007;86(9):1920-6. doi:10.1093/ps/86.9.1920.

12. Arshad MS, Anjum FM, Khan MI, Shahid M. Wheat germ oil and alpha-lipoic acid predominantly improve the lipid profile of broiler meat. J Agri food Chem. 2013;61(46):11158-65. doi:10.1021/jf4041029.

13. Haug A, Eich-Greatorex S, Bernhoft A, Wold JP, Hetland H, Christophersen $\mathrm{OA}$, et al. Effect of dietary selenium and omega-3 fatty acids on muscle composition and quality in broilers. Lipids Health Dis. 2007;6:29. doi:10.1186/1476-511X-6-29.

14. Jung $\mathrm{S}$, Choe JH, Kim B, Yun H, Kruk ZA, Jo C. Effect of dietary mixture of gallic acid and linoleic acid on antioxidative potential and quality of breast meat from broilers. Meat Sci. 2010;86(2):520-6. doi:10.1016/j.meatsci.2010.06.007.

15. Amaretti A, di Nunzio M, Pompei A, Raimondi S, Rossi M, Bordoni A. Antioxidant properties of potentially probiotic bacteria: in vitro and in vivo activities. Appl Microbiol Biotechnol. 2013;97(2):809-17. doi:10.1007/s00253-012-4241-7.

16. Chauhan R, Vasanthakumari AS, Panwar H, Mallapa RH, Duary RK, Batish VK, et al. Amelioration of colitis in mouse model by exploring antioxidative potentials of an indigenous probiotic strain of Lactobacillus fermentum Lf1. Biomed Res Int. 2014;2014:206732. doi:10.1155/2014/206732.

17. Martarelli D, Verdenelli MC, Scuri S, Cocchioni M, Silvi S, Cecchini C, et al. Effect of a probiotic intake on oxidant and antioxidant parameters in plasma of athletes during intense exercise training. Curr Microbiol. 2011;62(6):1689-96. doi:10.1007/s00284-011-9915-3.

18. Truusalu K, Naaber P, Kullisaar T, Tamm H, Mikelsaar R-H, Zilmer K, et al. The influence of antibacterial and antioxidative Probiotic lactobacilli on gut mucosa in a mouse model of Salmonella infection. Microb Ecol Health Dis. 2004;16(4):180-7. doi:10.1080/08910600410021783.

19. Douglas F, Hambleton R, Rigby GJ. An investigation of the oxidation-reduction potential and of the effect of oxygen on the germination and outgrowth of Clostridium butyricum spores, using platinum electrodes. J Appl Bacteriol. 1973;36(4):625-33. doi:10.1111/j.1365-2672.1973.tb04148.x.

20. Kong Q, He GQ, Jia JL, Zhu QL, Ruan H. Oral administration of Clostridium butyricum for modulating gastrointestinal microflora in mice. Curr Microbiol. 2011;62(2):512-7. doi:10.1007/s00284-010-9737-8.

21. Nakanishi S, Tanaka M. Sequence analysis of a bacteriocinogenic plasmid of Clostridium butyricum and expression of the bacteriocin gene in Escherichia coli. Anaerobe. 2010;16(3):253-7. doi:10.1016/j.anaerobe.2009.10.002.

22. Okamoto T, Sasaki M, Tsujikawa T, Fujiyama Y, Bamba T, Kusunoki M. Preventive efficacy of butyrate enemas and oral administration of Clostridium butyricum M588 in dextran sodium sulfate-induced colitis in rats. J Gastroenterol. 2000;35(5):341-6. doi:10.1007/s005350050358.

23. National Research Council. Nutrient requirements of poultry. 9th ed. Washington, DC: Natl Acad; 1994. p. 62.

24. Folch J, Lees M, Sloane Stanley GH. A simple method for the isolation and purification of total lipides from animal tissues. J Biol Chem. 1957;226(1):497-509.

25. Sacks FM. The role of high-density lipoprotein ( $\mathrm{HDL}$ ) cholesterol in the prevention and treatment of coronary heart disease: expert group recommendations. Am J Cardiol. 2002;90(2):139-43.

26. Suo C, Yin Y, Wang X, Lou X, Song D, Gu Q. Effects of lactobacillus plantarum ZJ316 on pig growth and pork quality. BMC Vet Res. 2012;8:89. doi:10.1186/1746-6148-8-89.

27. Endo T, Nakano M. Influence of a probiotic on productivity, meat components, lipid metabolism, caecal flora and metabolites, and raising environment in broiler production. Anim Sci J. 1999;70(4):207-18. doi:10.2508/chikusan.70.207.

28. Hosomi M, Tanida N, Shimoyama T. The role of intestinal bacteria in gallstone formation in animal model. A study on biliary lipid composition and bile acid profiles in bile, small intestinal contents and feces of Clostridium butyricum Miyairi No. 588 monocontaminated mice. Gastroenterol Jpn. 1982;17(4):316-23.

29. Kobashi K, Takeda Y, Itoh H, Hase J. Cholesterol-lowering effect of Clostridium butyricum in cholesterol-fed rats. Digestion. 1983;26(4):173-8.
30. Seo M, Inoue I, Tanaka M, Matsuda N, Nakano T, Awata T, et al. Clostridium butyricum MIYAIRI 588 improves high-fat diet-induced non-alcoholic fatty liver disease in rats. Dig Dis Sci. 2013;58(12):3534-44. doi:10.1007/s10620-013-2879-3.

31. Jin LZ, Ho YW, Abdullah N, Jalaludin S. Growth performance, intestinal microbial populations, and serum cholesterol of broilers fed diets containing Lactobacillus cultures. Poult Sci. 1998:77(9):1259-65.

32. Kalavathy R, Abdullah N, Jalaludin S, Ho YW. Effects of Lactobacillus cultures on growth performance, abdominal fat deposition, serum lipids and weight of organs of broiler chickens. Br Poult Sci. 2003;44(1):139-44. doi:10.1080/0007166031000085445.

33. Li L, Xu CL, Ji C, Ma Q, Hao K, Jin ZY, et al. Effects of a dried Bacillus subtilis culture on egg quality. Poult Sci. 2006;85(2):364-8.

34. Klaver FA, van der Meer R. The assumed assimilation of cholesterol by Lactobacilli and Bifidobacterium bifidum is due to their bile salt-deconjugating activity. Appl Environ Microbiol. 1993;59(4):1120-4.

35. Laparra JM, Sanz Y. I Interactions of gut microbiota with functional food components and nutraceuticals. Pharmacol Res. 2010;61(3):219-25. doi:10.1016/j.phrs.2009.11.001

36. Zhang WH, Gao F, Zhu QF, Li C, Jiang Y, Dai SF, et al. Dietary sodium butyrate alleviates the oxidative stress induced by corticosterone exposure and improves meat quality in broiler chickens. Poult Sci. 2011;90(11):2592-9. doi:10.3382/ps.2011-01446.

37. Maragkoudakis PA, Mountzouris KC, Rosu C, Zoumpopoulou G, Papadimitriou K, Dalaka E, et al. Feed supplementation of Lactobacillus plantarum PCA 236 modulates gut microbiota and milk fatty acid composition in dairy goats—a preliminary study. Int J Food Microbiol. 2010;141 Suppl 1:S109-16. doi:10.1016/j.ijfoodmicro.2010.03.007.

38. Chikunya S, Demirel G, Enser M, Wood JD, Wilkinson RG, Sinclair LA. Biohydrogenation of dietary n-3 PUFA and stability of ingested vitamin E in the rumen, and their effects on microbial activity in sheep. Br J Nutr. 2004;91(4):539-50. doi:10.1079/BJN20031078.

39. Endo H, Niioka M, Kobayashi N, Tanaka M, Watanabe T. Butyrate-producing probiotics reduce nonalcoholic fatty liver disease progression in rats: new insight into the probiotics for the gut-liver axis. PLOS ONE. 2013;8(5), e63388. doi:10.1371/journal.pone.0063388.

40. Junghare M, Subudhi S, Lal B. Improvement of hydrogen production under decreased partial pressure by newly isolated alkaline tolerant anaerobe, Clostridium butyricum TM-9A: Optimization of process parameters. Int J Hydrogen Energ. 2012;37(4):3160-8. doi:10.1016/j.ijhydene.2011.11.043.

41. Vandak D, Telgarsky M, Sturdik E. Influence of growth factor supplements on butyric acid production from sucrose by Clostridium butyricum. Folia Microbio. 1995;40(6):669-72. doi:10.1007/Bf02818528.

42. Courtois F, Seidman EG, Delvin E, Asselin C, Bernotti S, Ledoux M, et al. Membrane peroxidation by lipopolysaccharide and iron-ascorbate adversely affects Caco-2 cell function: beneficial role of butyric acid. Am J Clin Nutr. 2003;77(3):744-50.

43. Hamer HM, Jonkers DMAE, Bast A, Vanhoutvin SALW, Fischer MAJG, Kodde $A$, et al. Butyrate modulates oxidative stress in the colonic mucosa of healthy humans. Clin Nutr. 2009;28(1):88-93. doi:10.1016/j.clnu.2008.11.002.

44. Ohsawa I, Ishikawa M, Takahashi K, Watanabe M, Nishimaki K, Yamagata K, et al. Hydrogen acts as a therapeutic antioxidant by selectively reducing cytotoxic oxygen radicals. Nat Med. 2007;13(6):688-94. doi:10.1038/nm1577.

\section{Submit your next manuscript to BioMed Central and take full advantage of:}

- Convenient online submission

- Thorough peer review

- No space constraints or color figure charges

- Immediate publication on acceptance

- Inclusion in PubMed, CAS, Scopus and Google Scholar

- Research which is freely available for redistribution

Submit your manuscript at www.biomedcentral.com/submit

C Biomed Central 